\title{
Linear Free Energy Relationship Correlations for Room Temperature Ionic Liquids: Revised Cation-Specific and Anion-Specific Equation Coefficients for Predictive Applications Covering a Much Larger Area of Chemical Space
}

\author{
Laura M. Sprunger, ${ }^{\dagger}$ Jennifer Gibbs, ${ }^{\dagger}$ Amy Proctor ${ }^{\dagger}{ }^{\dagger}$ William E. Acree, Jr.,,${ }^{\dagger}$, \\ Michael H. Abraham, ${ }^{\ddagger}$ Yunjing Meng, ${ }^{\S}$ Cong Yao, ${ }^{\S}$ and Jared L. Anderson ${ }^{\S}$ \\ Department of Chemistry, P.O. Box 305070, University of North Texas, Denton, Texas 76203-5070, \\ Department of Chemistry, University College London, 20 Gordon Street, London, WC1H OAJ, and \\ Department of Chemistry, The University of Toledo, 2801 W. Bancroft Street MS 602, Toledo, Ohio 43606
}

\begin{abstract}
Previously reported ion-specific equation coefficients for both the Abraham general solvation model and Goss modified Abraham model are updated using recently measured activity coefficient, gas chromatographic retention factor, and solubility data for solutes dissolved in room temperature ionic liquids (RTILs). Reported for the first time are equation coefficients for 1-propyl-2,3-dimethylimidazolium cation, and octylsulfate and thiocyanate anions. In total nine sets of cation-specific and eight sets of anion-specific equation coefficients have been determined for each model. The derived correlations describe the 976 experimental gas-to-RTIL partition coefficients to within a standard deviation of $0.12 \mathrm{log}$ units and the 955 experimental water-to-RTIL partitions to within a standard deviation of $0.15 \log$ units.
\end{abstract}

\section{Introduction}

Room temperature ionic liquids (RTILs) have generated considerable interest recently because of their unique physical and chemical properties, high thermal stability, negligible vapor pressure, and high solvent capacity. New generation RTILs have increasingly become a solvent choice for applications involving organic synthesis and electrochemistry, extraction and chromatographic separations, and gas adsorption. The main advantage that ionic liquids offer over the more conventional organic solvents is that it is possible to modify the RTIL's physical and chemical properties simply by changing the cation and anion combinations. Physical and chemical properties are strongly influenced by the polarity, size, and geometric shape of the constituent ions. Ionic liquids are often referred to as designer solvents in the published chemical and engineering literature for this reason. While our understanding of the properties of ionic liquids has increased considerably in recent years, we are not yet to the point of being able to "tailor make" ionic liquids having specific physical and chemical properties.

The present study continues our characterization of the solubilizing properties of RTILs. Previously we have reported linear free energy relationship (LFER) correlations for the gasto-RTIL partition coefficients, $K$, for gas and organic vapors dissolved in RTILs ${ }^{1-3}$

$$
\begin{gathered}
\log K=c_{\text {cation }}+c_{\text {anion }}+\left(e_{\text {cation }}+e_{\text {anion }}\right) \cdot \mathbf{E}+\left(s_{\text {cation }}+\right. \\
\left.s_{\text {anion }}\right) \cdot \mathbf{S}+\left(a_{\text {cation }}+a_{\text {anion }}\right) \cdot \mathbf{A}+\left(b_{\text {cation }}+b_{\text {anion }}\right) \cdot \mathbf{B}+ \\
\left(l_{\text {cation }}+l_{\text {anion }}\right) \cdot \mathbf{L}(1) \\
\log K=c_{\text {cation }}+c_{\text {anion }}+\left(s_{\text {cation }}+s_{\text {anion }}\right) \cdot \mathbf{S}+\left(a_{\text {cation }}+\right. \\
\left.a_{\text {anion }}\right) \cdot \mathbf{A}+\left(b_{\text {cation }}+b_{\text {anion }}\right) \cdot \mathbf{B}+\left(l_{\text {cation }}+l_{\text {anion }}\right) \cdot \mathbf{L}+ \\
\left(v_{\text {cation }}+v_{\text {anion }}\right) \cdot \mathbf{V}(2)
\end{gathered}
$$

and for the partitioning of solutes between water and a RTIL, where $P$ is the water-to-RTIL partition coefficient

\footnotetext{
* To whom correspondence should be addressed. E-mail: acree@ unt.edu.

${ }^{\dagger}$ University of North Texas.

¥ University College London.

$\S$ The University of Toledo.
}

$$
\begin{array}{r}
\log P=c_{\text {cation }}+c_{\text {anion }}+\left(e_{\text {cation }}+e_{\text {anion }}\right) \cdot \mathbf{E}+\left(s_{\text {cation }}+\right. \\
\left.s_{\text {anion }}\right) \cdot \mathbf{S}+\left(a_{\text {cation }}+a_{\text {anion }}\right) \cdot \mathbf{A}+\left(b_{\text {cation }}+b_{\text {anion }}\right) \cdot \mathbf{B}+ \\
\left(v_{\text {cation }}+v_{\text {anion }}\right) \cdot \mathbf{V} \\
\log P=c_{\text {cation }}+c_{\text {anion }}+\left(s_{\text {cation }}+s_{\text {anion }}\right) \cdot \mathbf{S}+\left(a_{\text {cation }}+\right. \\
\left.a_{\text {anion }}\right) \cdot \mathbf{A}+\left(b_{\text {cation }}+b_{\text {anion }}\right) \cdot \mathbf{B}+\left(l_{\text {cation }}+l_{\text {anion }}\right) \cdot \mathbf{L}+ \\
\left(v_{\text {cation }}+v_{\text {anion }}\right) \cdot \mathbf{V}
\end{array}
$$

based on both the Abraham model (eqs 1 and 3$)^{4-10}$ and the Goss modified form of the Abraham model (eqs 2 and 4). ${ }^{11-16}$ The independent variables in eqs $1-4$ are solute descriptors as follows: $\mathbf{E}$ and $\mathbf{S}$ refer to the excess molar refraction in units of $\left(\mathrm{cm}^{3} \mathrm{~mol}^{-1}\right) / 10$ and dipolarity/polarizability descriptors of the solute, respectively, $\mathbf{A}$ and $\mathbf{B}$ are measures of the solute hydrogen-bond acidity and basicity, $\mathbf{V}$ is the McGowan volume in units of $\left(\mathrm{cm}^{3} \mathrm{~mol}^{-1}\right) / 100$ and $\mathbf{L}$ is the logarithm of the gasto-hexadecane partition coefficient at $298.15 \mathrm{~K}$. The regression coefficients and constants are determined by regression analyses of the experimental data for the given partition process.

The major advantage of splitting the equation coefficients into individual cation-specific and anion-specific contributions is that one can make predictions for more RTILs. Normally one needs partition coefficient data for 40-50 solutes dissolved in a given RTIL to develop a RTIL-specific Abraham model correlation. By combining all of the experimental data for a RTIL containing lets say either a 1-methyl-3-octylimidazolium cation, $[\mathrm{MOIm}]^{+}$, and trifluoromethanesulfonate anion, $[\text { Trif }]^{-}$, it may be possible to calculate $[\mathrm{MOIm}]^{+}$-specific and $[\text {Trif }]^{-}$-specific equation coefficients where there was too few data points for the $[\mathrm{MOIm}]^{+}[\text {Trif }]^{-}$ionic liquid to develop a meaningful correlation. The computational methodology that we proposed permits us to calculate more ion-specific equation coefficients as more experimental data becomes available in the future, and the basic computational methodology can be applied to LFERs that employ different kinds/types of solute descriptors.

To date, we have determined equation coefficients for eight cations and six anions using a database that contained 663 experimental $\log K$ and 649 experimental $\log P$ values. ${ }^{1-3}$ Most of the experimental $\log K$ and $\log P$ values used in our regression 
analyses have come from gas solubilities and infinite dilution activity coefficients determined by gas-liquid chromatographic measurements. Solutes studied have typically been inert gases, diatomic gas molecules, linear and branched alcohols, linear and cyclic monoethers (plus 1,4-dioxane), alkanoates, chlorinated methanes, and a few small aldehydes and ketones. The solute descriptor space defined by these compounds would be $\mathbf{E}=0.000$ to $\mathbf{E}=0.850 ; \mathbf{S}=0.000$ to $\mathbf{S}=0.900 ; \mathbf{A}=0.000$ to $\mathbf{A}=0.430 ; \mathbf{B}=0.000$ to $\mathbf{B}=0.650 ; \mathbf{V}=0.109$ to $\mathbf{V}=$ 1.800; and $\mathbf{L}=-1.200$ to $\mathbf{L}=5.700$. A few of the ion-specific data sets spanned a slightly smaller range of solute descriptors. The ion-specific equation coefficients that we have determined should allow one to make reasonably accurate partition coefficient predictions for most solutes having solute descriptors that fall within the aforementioned ranges.

Since the publication of our last paper we have become aware of gas chromatographic retention factor data for several polar aromatic solutes and carboxylic acids on liquid 1-butyl-3methylimidazoliumbis(trifluoromethylsulfonyl)imide, ([BMIm] $]^{+}$$\left.\left[(\mathrm{Tf})_{2} \mathrm{~N}\right]^{-}\right),{ }^{17}$ 1-butyl-3-methylimidazolium hexafluorophosphate, $\left([\mathrm{BMIm}]^{+}\left[\mathrm{PF}_{6}\right]^{-}\right),{ }^{18}$ and 1-butyl-3-methylimidazolium octylsulfate, $\left([\mathrm{BMIm}]^{+}\left[\mathrm{OtSO}_{4}\right]^{-}\right)^{18}$ stationary phases, and of solubility data for caffeine and acetaminophen in 1-methyl-3octylimidazolium tetrafluoroborate, $\left([\mathrm{MOIm}]^{+}\left[\mathrm{BF}_{4}\right]^{-}\right)$, in 1-methyl-3-octylimidazolium hexafluorophosphate, ([MOIm $]^{+}$$\left.\left[\mathrm{PF}_{6}\right]^{-}\right)$, in $\left([\mathrm{BMIm}]^{+}\left[\mathrm{PF}_{6}\right]^{-}\right)$, and in 1-butyl-3-methylimidazolium tetrafluoroborate, $\left([\mathrm{BMIm}]^{+}\left[\mathrm{BF}_{4}\right]^{-}\right) .{ }^{19}$ Solutes used in these latter studies fall well outside of the predictive area of chemical space of our derived ion-specific equation coefficients. For example, the hydrogen-bond acidity descriptors of acetic acid $(\mathbf{A}=0.610)$, acetaminophen $(\mathbf{A}=1.040)$, propionic acid $(\mathbf{A}=$ $0.600)$ and phenol $(\mathbf{A}=0.600)$ are much larger than those of linear alcohols, which typically fall in the $\mathbf{A}=0.310$ to $\mathbf{A}=$ 0.430 range. Several of the polar aromatic solutes used in the chromatographic retention factor studies had $\mathbf{E}$ and/or $\mathbf{S}$ solute descriptors greater than unity. The data set used in calculating our existing ion-specific equation coefficients contained solutes with much smaller $\mathbf{E}$ and $\mathbf{S}$ solute descriptors. Naphthalene, the single polycyclic aromatic hydrocarbon solute in the retention factor data sets had an $\mathbf{E}$ value of $\mathbf{E}=1.340$.

There are sufficient new experimental $\log K$ and $\log P$ values for compounds outside of the chemical space of our existing ion-specific equation coefficients to warrant a redetermination. Numerical values computed from the reanalysis should give much better predictions, particularly for the more acidic and/or polarizable compounds. Our current set of Abraham model equation coefficients overpredicts the gas-to-RTIL partition coefficients of acetaminophen in all three ionic liquids: $\left([\mathrm{MOIm}]^{+}\left[\mathrm{BF}_{4}\right]^{-}\right)(\log K($ calcd $)=11.75$ versus $\log K$ (exptl) $=11.03)$; in $\left([\mathrm{MBIm}]^{+}\left[\mathrm{PF}_{6}\right]^{-}\right)(\log K($ calcd $)=11.29$ versus $\log K($ exptl $)=10.65)$; and in $\left([\mathrm{MOIm}]^{+}\left[\mathrm{PF}_{6}\right]^{-}\right)(\log K($ calcd $)$ $=11.05$ versus $\log K($ exptl $)=9.93)$ by $0.6 \log$ units or more. Four of the five solute descriptors for acetaminophen $(\mathbf{E}=$ $1.060, \mathbf{S}=1.630, \mathbf{A}=1.060$, and $\mathbf{L}=6.870$ ) were outside of the predictive area of chemical space for eq 1 . As part of the present study we also report equation coefficients for one additional cation (1-propyl-2,3-dimethylimidazolium, $\left[\mathrm{PM}_{2}-\right.$ $\mathrm{Im}]^{+}$), and two additional anions (octylsulfate, $\left[\mathrm{OtSO}_{4}\right]^{-}$; and thiocyanate, $[\mathrm{SCN}]^{-}$).

\section{Data Set and Computational Methodology}

The majority of the experimental $\log K$ and $\log P$ values were reported in the Supporting Information that accompanied two earlier papers. ${ }^{1,2}$ Experimental $\log K$ and $\log P$ data for nonpolar and polar organic solutes dissolved in 1-methyl-3-butylimidazolium trifluoromethylsulfonate, $\left([\mathrm{MBIm}]^{+}[\text {Trif }]^{-}\right)$, and in 1-methyl-3-ethylimidazolium trifluoroacetate, ([MEIm $]^{+}$$\left[\mathrm{F}_{3} \mathrm{Ac}\right]^{-}$), are given in an earlier publication ${ }^{3}$ that reported anionspecific equation coefficients for the trifluoromethylsulfonate and trifluoroacetate anions. Most of the new experimental data that we were able to retrieve from the published literature ${ }^{20-38}$ pertained to the infinite dilution activity coefficient, $\gamma_{\text {solute }}^{\infty}$, for solutes dissolved in RTILs or to the Henry's law constants, $K_{\text {Henry }}$, for gases dissolved in RTILs. To apply the Abraham model and Goss-modified Abraham model the infinite dilution activity coefficients and Henry's law constants needed to be converted to $\log K$ values through eqs 5 and 6

$$
\begin{gathered}
\log K=\log \left(\frac{R T}{\gamma_{\text {solute }}^{\infty} P_{\text {solute }}^{\mathrm{o}} V_{\text {solvent }}}\right) \\
\log K=\log \left(\frac{R T}{K_{\text {Henry }} V_{\text {solvent }}}\right)
\end{gathered}
$$

or $\log P$ values for partition from water to the ionic liquid through eq 7

$$
\log P=\log K-\log K_{\mathrm{w}}
$$

In equations $5-7 R$ is the universal gas constant, $T$ is the system temperature, $P_{\text {solute }}^{\circ}$ is the vapor pressure of the solute at $T$, and $V_{\text {solvent }}$ is the molar volume of the solvent. The calculation of $\log P$ requires knowledge of the solute's gas phase partition coefficient into water, $K_{\mathrm{w}}$, which is available for most of the solutes being studied.

Gas-to-ionic liquid partition coefficients can also be calculated from experimental molar solubility data for solutes dissolved in RTILs and from liquid-liquid equilibrium data for partly miscible binary RTIL plus organic solvent mixtures. As noted in the preceding section, Mizuuchi et al. ${ }^{19}$ measured the solubilities of caffeine and acetaminophen in $\left([\mathrm{MOIm}]^{+}\left[\mathrm{BF}_{4}\right]^{-}\right)$, $\left([\mathrm{MOIm}]^{+}\left[\mathrm{PF}_{6}\right]^{-}\right)$and $\left([\mathrm{BMIm}]^{+}\left[\mathrm{BF}_{4}\right]^{-}\right)$. Alonso et al. ${ }^{39-45}$ and others $^{46-52}$ have reported liquid-liquid equilibrium data and phase diagrams for binary mixtures containing an ionic liquid with linear and branched alkanes, cycloalkanes and 1,3propanediol. The water-to-ionic liquid partition coefficient is calculated as the ratio of the solute's molar solubility in the

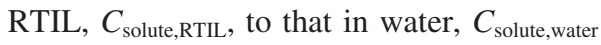

$$
P=C_{\text {solute, } \mathrm{RTIL}} / C_{\text {solute, water }}
$$

The gas-to-RTIL partition coefficient is calculated in similar fashion as

$$
\begin{gathered}
K=C_{\text {solute, RTIL }} / C_{\text {solute,gas }} \\
C_{\text {solute,gas }}=P_{\text {solute }}^{\mathrm{o}} /(R T)
\end{gathered}
$$

the ratio of the solute's molar solubility in the RTIL divided by the gas phase concentration, with the latter quantity being calculated from the vapor pressure of the solute at the system temperature of $298.15 \mathrm{~K}$ via eq 10 . Equations 8 and 9 apply to both liquid and crystalline solutes and require that the equilibrium solute phase be that of the pure liquid or solid solute.

Experimental gas chromatographic retention factors on $\left([\mathrm{BMIm}]^{+}\left[(\mathrm{Tf})_{2} \mathrm{~N}\right]^{-}\right)$were from a study ${ }^{17}$ that explored the feasibility of using binary ionic liquid mixtures as chromatographic stationary phases for improving the separation selectivity of alcohols and aromatic compounds. The 1-butyl-3-methylimidazolium hexafluorophosphate $\left([\mathrm{BMIm}]^{+}\left[\mathrm{PF}_{6}\right]^{-}\right)$column was 
Table 1. Logarithm of Chromatographic Retention Factors for Solutes Dissolved in $\left.[\mathrm{BMIm}]^{+}\left[(\mathrm{Tf})_{2} \mathrm{~N}\right]^{-}\right),\left[\mathrm{BMIm}^{+}\left[\mathrm{PF}_{6}\right]^{-}\right)$, and $\left([\mathrm{BMIm}]^{+}\left[\mathrm{OtSO}_{4}\right]^{-}\right.$) Based on Gas Chromatographic Retention Measurements

\begin{tabular}{|c|c|c|c|}
\hline solute & $\begin{array}{l}{[\mathrm{BMIm}]^{+}} \\
{\left[(\mathrm{Tf})_{2} \mathrm{~N}\right]^{-}}\end{array}$ & $\begin{array}{c}{\left[\mathrm{BMIm}^{+}\right.} \\
{\left[\mathrm{PF}_{6}\right]^{-}}\end{array}$ & $\begin{array}{l}{[\mathrm{BMIm}]^{+}} \\
{\left[\mathrm{OtSO}_{4}\right]^{-}}\end{array}$ \\
\hline 1,2-dichlorobenzene & 1.708 & 1.690 & 1.972 \\
\hline 1,4-dioxane & 1.052 & 0.977 & \\
\hline 1-bromohexane & 0.975 & & 1.010 \\
\hline 1-bromooctane & 1.559 & 1.324 & 1.762 \\
\hline 1-butanol & 0.966 & 0.724 & 1.359 \\
\hline 1-chlorohexane & 0.653 & & 0.613 \\
\hline 1-chlorooctane & 1.256 & 1.013 & 1.500 \\
\hline 1-decanol & 3.142 & 2.744 & \\
\hline 1-iodobutane & & & 0.578 \\
\hline 1-nitropropane & 1.309 & 1.444 & 1.055 \\
\hline 1-octanol & 2.208 & 1.943 & \\
\hline 1-pentanol & 1.237 & 1.097 & 1.828 \\
\hline 2-chloroaniline & 3.236 & & \\
\hline 2-pentanone & 0.951 & 0.925 & \\
\hline 2-propanol & 0.422 & & \\
\hline acetic acid & 1.402 & 1.131 & \\
\hline acetophenone & 2.889 & 2.847 & 2.434 \\
\hline aniline & 3.076 & & \\
\hline benzaldehyde & 2.316 & 2.367 & 2.081 \\
\hline benzene & 0.425 & 0.251 & -0.081 \\
\hline benzonitrile & 2.511 & 2.526 & 2.291 \\
\hline benzyl alcohol & 3.252 & & \\
\hline butanal & 0.490 & & \\
\hline cyclohexanol & & 1.625 & 2.473 \\
\hline cyclohexanone & 1.870 & 1.738 & 1.268 \\
\hline$N, N$-dimethylformamide & 2.357 & 2.419 & \\
\hline ethyl acetate & 0.504 & 0.250 & \\
\hline ethyl benzene & 0.968 & 0.794 & 0.801 \\
\hline methyl caproate & 1.391 & 1.120 & 1.072 \\
\hline naphthalene & 2.907 & 2.705 & 2.597 \\
\hline nitrobenzene & 2.629 & 2.934 & 2.632 \\
\hline 2-nitrophenol & & 2.879 & \\
\hline octylaldehyde & 1.777 & 1.508 & 1.702 \\
\hline phenetole & 1.830 & 1.751 & 1.605 \\
\hline phenol & & 3.135 & \\
\hline propionic acid & & 1.433 & \\
\hline propionitrile & 0.885 & 0.887 & 0.332 \\
\hline pyridine & 1.149 & 1.282 & \\
\hline pyrrole & 1.898 & & 2.448 \\
\hline toluene & 0.753 & & 0.420 \\
\hline$m$-xylene & 1.113 & 0.881 & 0.823 \\
\hline$o$-xylene & 1.235 & 1.067 & 0.962 \\
\hline$p$-xylene & 1.100 & 0.891 & 0.813 \\
\hline
\end{tabular}

prepared by coating the ionic liquid on an untreated glass column. The chromatographic experiments were performed at slightly higher temperatures of 40,70 , and $100{ }^{\circ} \mathrm{C}$. Numerical values at $25^{\circ} \mathrm{C}$ were obtained through a linear $\log k$ versus $1 / T$ (with $T$ in Kelvin) plot of the measured $\log k$ data at 40 and 70 ${ }^{\circ} \mathrm{C}$. The calculated $\log k$ values at $25^{\circ} \mathrm{C}$ are tabulated in Table 1. The gas to liquid partition coefficient can be obtained from isothermal chromatographic measurements through $K=V_{\mathrm{N}} / V_{\mathrm{L}}$ where $V_{\mathrm{N}}$ is the volume of gas required to elute a solute, and $V_{\mathrm{L}}$ is the volume of liquid present as the stationary phase. The retention factor, $k$, is given by ${ }^{17} k=\left(t_{\mathrm{r}}-t_{\mathrm{m}}\right) / t_{\mathrm{m}}$ where $t_{\mathrm{r}}$ is the retention time of a solute and $t_{\mathrm{m}}$ is the "void" retention time. Since $t_{\mathrm{r}}-t_{\mathrm{m}}$, the corrected retention time, is proportional to $V_{\mathrm{N}}$, the corrected elution volume, it follows that gas-to-liquid partition coefficients and retention factors are interrelated,

$$
K=P^{*} k \quad \text { or } \quad \log K=\log P^{*}+\log k
$$

To a first approximation, the proportionality constant, $P^{*}$, is the phase ratio and depends only on chromatographic conditions that should remain constant for a given column during the time the experimental measurements are performed. The proportionality constants used in conversions, $\log P^{*}=2.482$ for $\left([\mathrm{BMIm}]^{+}\left[\mathrm{Tf}_{2} \mathrm{~N}\right]^{-}\right)$and $\log P^{*}=2.489$ for $\left([\mathrm{BMIm}]^{+}\right.$-
$\left[\mathrm{PF}_{6}\right]^{-}$), were the calculated average difference between the measured $\log k$ and $\log K$ data for 10 common compounds in the $\log k$ and $\log K$ data sets. The two proportionality constants are essentially identical as theoretically expected. A $0.28 \mu \mathrm{m}$ film thickness was used for both ionic liquid stationary phases. The 1-butyl-3-methylimidazolium octylsulfate column was prepared by coating the ionic liquid on a deactivated glass column, and the calculated proportionality constant based on $\log k$ and $\log K$ data for a set of common compounds and an Abraham model regression analysis of the experimental $\log k$ and $\log K$ data for only $[\mathrm{BMIm}]^{+}\left[\mathrm{OtSO}_{4}\right]^{-}$was slightly larger, $\log P^{*}=2.978$. The experimental $\log k$ data for the $[\mathrm{BMIm}]^{+}\left[\mathrm{OtSO}_{4}\right]^{-}$, extrapolated back to $298 \mathrm{~K}$, is also given in Table 1.

In total, our search of the published chemical literature found experimental molar solubilities, Henry's law constants, infinite dilution activity coefficients, and gas chromatographic retention factors for 976 solute-RTIL pairs. The experimental values were converted to $\log K$ and $\log P$ values through eqs $5-11$. For convenience we have compiled in Tables S1 and S2 (Supporting Information) the entire database of calculated $\log K$ and $\log P$ values, along with the solute descriptors for all of the compounds considered in the present study. The solute descriptors are of experimental origin and came from our solute descriptor database, which now contains values for more than 4000 different organic and organometallic compounds.

A few additional comments concern the computational methodology that we will employ in this study. The cationspecific and anion-specific coefficients in eqs 1-4 are paired. Each cation-specific coefficient goes together with its anionspecific counterpart to make up a summed value that the five solute descriptors are multiplied by. If one were to perform a regression analysis on eqs $1-4$ the statistical software would generate numerical equation coefficients based on some reference point. The reference point would likely depend on the particular database used and the software's built-in convergence routine. Calculation of additional ion values at some later time would be difficult as there is no guarantee that the next regression analyses would find the same reference point. In accordance with the computational methodology that we recommended in our earlier papers ${ }^{1-3}$ we have set the anion-specific equation coefficients of $\left[(\mathrm{Tf})_{2} \mathrm{~N}\right]^{-}$equal to zero. In many respects our fixed reference point is analogous to how the chemical potentials of the individual ions are determined. By convention the chemical potential of the hydrogen ion is defined to be zero, and the values of all other ions are computed relative to this defined thermodynamic reference state.

\section{Results and Discussion}

The 976 experimental $\log K$ values were analyzed collectively by regression analysis to yield the following correlations.

Abraham model:

$$
\begin{gathered}
\log K=\sum_{\text {cation }}\left(c_{\text {cation }}+e_{\text {cation }} \mathbf{E}+s_{\text {cation }} \mathbf{S}+a_{\text {cation }} \mathbf{A}+\right. \\
\left.b_{\text {cation }} \mathbf{B}+l_{\text {cation }} \mathbf{L}\right)+ \\
\sum_{\text {anion }}\left(c_{\text {anion }}+e_{\text {anion }} \mathbf{E}+s_{\text {anion }} \mathbf{S}+a_{\text {anion }} \mathbf{A}+b_{\text {anion }} \mathbf{B}+l_{\text {anion }} \mathbf{L}\right) \\
\left(N=976, R^{2}=0.999, R_{\text {adj }}^{2}=0.998, \mathrm{SD}=0.116, F=6163\right)
\end{gathered}
$$

Goss-modified Abraham model: 


$$
\begin{gathered}
\log K=\sum_{\text {cation }}\left(c_{\text {cation }}+s_{\text {cation }} \mathbf{S}+a_{\text {cation }} \mathbf{A}+b_{\text {cation }} \mathbf{B}+\right. \\
\left.v_{\text {cation }} \mathbf{V}+l_{\text {cation }} \mathbf{L}\right)+ \\
\sum_{\text {anion }}\left(c_{\text {anion }}+s_{\text {anion }} \mathbf{S}+a_{\text {anion }} \mathbf{A}+b_{\text {anion }} \mathbf{B}+v_{\text {anion }} \mathbf{V}+l_{\text {anion }} \mathbf{L}\right) \\
\left(N=976, R^{2}=0.998, R_{\text {adj }}^{2}=0.998, \mathrm{SD}=0.119, F=5860\right)
\end{gathered}
$$

The calculated cation-specific and anion-specific equation coefficients for eqs 12 and 13 are listed in Tables 2 and 3, respectively. The standard errors in the coefficients are given in parentheses directly below the respective values. For the most part, the larger standard errors are noted in the equation coefficients for those ions for which experimental data is limited. Here and elsewhere $N$ is the number of data points, SD denotes the standard deviation, $R^{2}$ gives the squared correlation coefficient and $F$ corresponds to the Fisher's $F$ statistic. Regression analyses were performed using SPSS statistical software. Both correlations are statistically very good, and describe an experimental $\log K$ database that covers a $12.5 \log$ unit range to within standard deviations of $0.116 \log$ units (eq 12) and $0.119 \log$ units (eq 13). The number of data points for the individual ions ranges from a minimum of $28 \log K$ values for the $[\mathrm{SCN}]^{-}$ion to more than $350 \log K$ values for the both [BMIm] ${ }^{+}$cation and $\left[(\mathrm{Tf})_{2} \mathrm{~N}\right]^{-}$anion, which is sufficient for the regression analyses. Figures 1 and 2 depict a plot of the experimental $\log K$ data versus the calculated values based on the Abraham model and the Goss-modified Abraham model. Each calculation uses only the values for the cation and anion in the given RTIL. For example, the correlation equations used to calculate the $\log K$ values for 1-methyl-3-butylimidazolium bis(trifluoromethylsulfonyl)imide, $\left([\mathrm{MBIm}]^{+}\left[(\mathrm{Tf})_{2} \mathrm{~N}\right]^{-}\right)$ionic liquid would be the following:

Abraham model:

$\log K=-0.428(0.025)+0.137(0.067) \mathbf{E}+$

$$
1.961(0.080) \mathbf{S}+2.179(0.097) \mathbf{A}+0.946(0.104) \mathbf{B}+
$$
$0.694(0.008) \mathbf{L}(14)$

Goss-modified Abraham model:

$\log K=-0.456(0.054)+2.130(0.094) \mathbf{S}+$

$$
2.269(0.102) \mathbf{A}+0.811(0.097) \mathbf{B}+0.676(0.038) \mathbf{L}+
$$
$0.093(0.152) \mathbf{V}$

constructed from the $[\mathrm{MBIm}]^{+}$-specific and $\left[(\mathrm{Tf})_{2} \mathrm{~N}\right]^{-}$-specific equation coefficients given in Tables 2 and 3. The resulting correlations are in good agreement with the RTIL-specific correlation equations.

Abraham model:

$$
\begin{aligned}
& \log K=-0.366(0.029)+0.148(0.067) \mathbf{E}+ \\
& 1.946(0.085) \mathbf{S}+2.261(0.098) \mathbf{A}+0.872(0.107) \mathbf{B}+
\end{aligned}
$$

Goss-modified Abraham model:

$$
\begin{aligned}
& \log K=-0.394(0.062)+ 2.057(0.107) \mathbf{S}+ \\
& 2.341(0.109) \mathbf{A}+0.771(0.105) \mathbf{B}+ \\
& 0.708(0.045) \mathbf{L}-0.018(0.179) \mathbf{V}
\end{aligned}
$$

\begin{tabular}{|c|c|c|c|c|c|c|}
\hline ion & $c_{\text {ion }}$ & $e_{\text {ion }}$ & $s_{\text {ion }}$ & $a_{\text {ion }}$ & $b_{\text {ion }}$ & $l_{\text {ion }}$ \\
\hline \multicolumn{7}{|c|}{ Cations $^{a}$} \\
\hline $\begin{array}{l}\left.{ }^{[\mathrm{MEIm}}\right]^{+} \\
(N=210)^{b}\end{array}$ & $\begin{array}{c}-0.526 \\
(0.028)\end{array}$ & $\begin{array}{c}0.248 \\
(0.99)\end{array}$ & $\begin{array}{l}2.286 \\
(0.100)\end{array}$ & $\begin{array}{l}2.319 \\
(0135)\end{array}$ & $\begin{array}{l}1.047 \\
(0.112)\end{array}$ & $\begin{array}{c}0.641 \\
(0.010)\end{array}$ \\
\hline [BMIm $^{+}$ & -0.427 & 0.137 & 1.961 & 2.179 & 0.946 & 0.694 \\
\hline$(N=354)$ & $(0.025)$ & $(0.067)$ & $(0.080)$ & $(0.097)$ & (0.104) & $(0.008)$ \\
\hline$\left[\mathrm{MHIm}^{+}\right.$ & -0.395 & -0.062 & 1.975 & 2.234 & 0.621 & 0.768 \\
\hline$(N=118)$ & $(0.030)$ & $(0.093)$ & (0.103) & (0.129) & $(0.11$ & (0.009) \\
\hline$\left[\mathrm{MOIm}^{+}\right.$ & -0.266 & -0.218 & 1.218 & 1.642 & 1.317 & 0.832 \\
\hline$(N=91)$ & $(0.036)$ & $(0.111)$ & $(0.140)$ & (0.136) & $(0.159)$ & $(0.011)$ \\
\hline$\left[\mathrm{M}_{3} \mathrm{BAm}\right]^{+}$ & -0.457 & -0.005 & 2.188 & 2.375 & 0.663 & 0.668 \\
\hline$(N=58)$ & $(0.046)$ & $(0.127)$ & $(0.146)$ & (0.193) & $(0.191)$ & $(0.012)$ \\
\hline$\left[\mathrm{M}_{2} \mathrm{EIm}\right]^{+}$ & -0.611 & 0.188 & 2.380 & 2.101 & 0.899 & 0.667 \\
\hline$(N=39)$ & $(0.074)$ & (0.139) & (0.147) & $(0.181)$ & $(0.142)$ & $(0.022)$ \\
\hline$[\mathrm{BMPy}]^{+}$ & -0.489 & 0.257 & 2.127 & 1.878 & 1.133 & 0.674 \\
\hline$(N=41)$ & $(0.069)$ & $(0.161)$ & $(0.177)$ & $(0.216)$ & $(0.190)$ & $(0.022)$ \\
\hline$[\mathrm{NEP}]^{+}$ & -0.668 & 0.246 & 2.399 & 2.403 & 0.936 & 0.672 \\
\hline$(N=31)$ & $(0.079)$ & (0.198) & (0.186) & $(0.216)$ & $(0.155)$ & $(0.029)$ \\
\hline$\left[\mathrm{PM}_{2} \mathrm{Im}\right]^{+}$ & -0.863 & 0.820 & 2.317 & 3.216 & 1.092 & 0.513 \\
\hline$(N=34)$ & $(0.124)$ & $(0.186)$ & $(0.219)$ & $(0.253)$ & $(0.236)$ & $(0.037)$ \\
\hline \multicolumn{7}{|c|}{ Anions ${ }^{c}$} \\
\hline $\begin{array}{l}{\left[(\mathrm{Tf})_{2} \mathrm{~N}\right]^{-}} \\
(N=401)\end{array}$ & 0.000 & 0.000 & 0.000 & 0.000 & 0.000 & 0.000 \\
\hline$\left[\mathrm{BF}_{4}\right]^{-}$ & -0.162 & 0.177 & 0.411 & 1.309 & -0.574 & -0.055 \\
\hline$(N=225)$ & $(0.030)$ & $(0.093)$ & (0.111) & (0.133) & $(0.132)$ & $(0.01$ \\
\hline$\left[\mathrm{PF}_{6}\right]^{-}$ & -0.085 & -0.297 & 0.730 & 0.070 & -0.629 & -0.054 \\
\hline$(N=108)$ & $(0.033)$ & $(0.08$ & $(0.101)$ & $(0.116)$ & $(0.1$ & $(0.012)$ \\
\hline$\left[\mathrm{EtSO}_{4}\right]^{-}$ & -0.151 & -0.232 & 0.259 & 2.995 & -1.034 & -0.054 \\
\hline$(N=53)$ & $(0.065)$ & $(0.155)$ & $(0.172)$ & $(0.223)$ & $(0.200)$ & $(0.018)$ \\
\hline$[\text { Trif }]^{-}$ & -0.283 & -0.023 & 0.391 & 1.782 & -0.446 & 0.012 \\
\hline$(N=73)$ & $(0.051)$ & $(0.132)$ & (0.149) & (0.171) & (0.147) & $(0.017)$ \\
\hline$\left[\mathrm{F}_{3} \mathrm{Ac}\right]^{-}$ & -0.299 & -0.242 & 0.395 & 3.148 & -0.291 & 0.033 \\
\hline$(N=30)$ & $(0.063)$ & $(0.322)$ & $(0.490)$ & $(0.715)$ & $(0.811)$ & $(0.021)$ \\
\hline$\left[\mathrm{OtSO}_{4}\right]^{-}$ & 0.291 & -0.312 & -0.041 & 2.510 & -1.205 & 0.128 \\
\hline$(N=58)$ & $(0.075)$ & (0.109) & $(0.130)$ & $(0.189)$ & $(0.174)$ & $(0.019)$ \\
\hline$[\mathrm{SCN}]^{-}$ & -0.667 & -0.200 & 1.477 & 3.385 & -1.640 & -0.022 \\
\hline$(N=28)$ & $(0.123)$ & $(0.324)$ & $(0.497)$ & $(0.754)$ & $(0.821)$ & $(0.036)$ \\
\hline
\end{tabular}

obtained by regression analysis of the $\log K$ data for only $\left([\mathrm{MBIm}]^{+}\left[(\mathrm{Tf})_{2} \mathrm{~N}\right]^{-}\right)$. Solutes in the $\left([\mathrm{MBIm}]^{+}\left[(\mathrm{Tf})_{2} \mathrm{~N}\right]^{-}\right)$data set cover approximately the same area of chemical space as the entire RTIL database that was used in determining the ionspecific equation coefficients. In splitting the equation coefficients into cation-specific and anion-specific interactions we have assumed that each given solute-ion interaction is unaffected
Table 2. Cation-Specific and Anion-Specific Equation Coefficients for the Abraham Model Gas-to-RTIL Correlation (eq 12)

${ }^{a}$ Cation abbreviations: $[\mathrm{BMPy}]^{+}$is 4 -methyl- $N$-butylpyridinium cation; $[\mathrm{MEIm}]^{+}$is 1 -methyl-3-ethylimidazolium cation; $\left[\mathrm{M}_{2} \mathrm{EIm}\right]^{+}$is 1,2-dimethyl-3-ethylimidazolium cation; $[\mathrm{MBIm}]^{+}$is 1-methyl-3butylimidazolium cation; $[\mathrm{MHIm}]^{+}$is1-methyl-3-hexylimidazolium cation; $\left[\mathrm{M}_{3} \mathrm{BAm}\right]^{+}$is trimethylbutylammonium cation; $[\mathrm{MOIm}]^{+}$is 1-methyl-3-octylimidazolium cation; $[\mathrm{NEPy}]^{+}$is $\mathrm{N}$-ethylpyridinium cation; and $\left[\mathrm{PM}_{2} \mathrm{Im}\right]^{+}$is 1-propyl-2,3-dimethyl-imidazolium cation. ${ }^{b}$ Number of experimental data points associated with the specified ion. ${ }^{c}$ Anion abbreviations: [(Tf $\left.)_{2} \mathrm{~N}\right]^{-}$is bis(trifluoromethylsulfonyl)imide anion; $\left[\mathrm{BF}_{4}\right]^{-}$is tetrafluoroborate anion; $\left[\mathrm{PF}_{6}\right]^{-}$is hexafluorophosphate anion; $\left[\mathrm{EtSO}_{4}\right]^{-}$is ethylsulfate anion; $[\mathrm{Trif}]^{-}$is the trifluoromethanesulfonate anion; $\left[\mathrm{F}_{3} \mathrm{Ac}\right]^{-}$is the trifluoroacetate anion; $\left[\mathrm{OtSO}_{4}\right]^{-}$ is octylsulfate anion; and $[\mathrm{SCN}]^{-}$is thiocyanate anion.

by the nature of the other co-ion present in the RTIL. For the RTILs studied thus far, this appears to be a good approximation as evidenced by both the predictive ability of the derived correlations, and the fact that many of the RTIL-specific correlations are in reasonably good agreement with correlations obtained by combining the cation-specific and anion-specific equation coefficients (eq 14 versus eq 16, and eq 15 versus eq 17).

As noted above, the recalculation of ion-specific equation coefficients was prompted by the observation that the previous numerical values overpredicted the gas-to-RTIL partition coefficients of acetaminophen in 1-methyl-3-octylimidazolium tetrafluoroborate, $\left([\mathrm{MOIm}]^{+}\left[\mathrm{BF}_{4}\right]^{-}\right)$, in 1-methyl-3-octylimidazolium hexafluorophosphate, $\left([\mathrm{MOIm}]^{+}\left[\mathrm{PF}_{6}\right]^{-}\right)$, in $\left([\mathrm{BMIm}]^{+}-\right.$ $\left.\left[\mathrm{PF}_{6}\right]^{-}\right)$, and in 1-butyl-3-methylimidazolium tetrafluoroborate, $\left([\mathrm{BMIm}]^{+}\left[\mathrm{BF}_{4}\right]^{-}\right)$. The calculated $\log K$ values were $0.6 \log$ units or more larger than the experimental values based on the recently published acetaminophen solubility data: ${ }^{19}$ $\left([\mathrm{MOIm}]^{+}\left[\mathrm{BF}_{4}\right]^{-}\right)(\log K($ calcd $)=11.75$ versus $\log K$ (exptl) 
Table 3. Cation-Specific and Anion-Specific Equation Coefficients for the Goss-Modified Abraham Model Gas-to-RTIL Set Correlation (eq 13)

\begin{tabular}{|c|c|c|c|c|c|c|}
\hline $\operatorname{ion}^{a}$ & $c_{\text {ion }}$ & $s_{\text {ion }}$ & $a_{\text {ion }}$ & $b_{\text {ion }}$ & $l_{\text {ion }}$ & $v_{\text {ion }}$ \\
\hline \multicolumn{7}{|c|}{ Cations } \\
\hline$[\mathrm{MEIm}]^{+}$ & -0.434 & 2.349 & 2.347 & 0.926 & 0.724 & -0.296 \\
\hline $\begin{array}{l}(N=210)^{b} \\
{\text { [BMIm }]^{+}}^{2}\end{array}$ & $\begin{array}{r}(0.065) \\
-0.456\end{array}$ & $\begin{array}{r}(0.1 \\
2.1\end{array}$ & $\begin{array}{c}(0.148) \\
2.269\end{array}$ & $\begin{array}{c}(0.109) \\
0.811\end{array}$ & & $\begin{array}{c}(0.178) \\
0.094\end{array}$ \\
\hline$(N=354)$ & $\begin{array}{c}-0.456 \\
(0.054)\end{array}$ & $(0.094)$ & $(0.101)$ & (0.097) & (0.038) & $\begin{array}{l}0.094 \\
(0.152)\end{array}$ \\
\hline$\left[\mathrm{MHIm}^{+}\right.$ & -0.394 & 1.923 & 2.213 & 0.663 & 0.760 & 0.020 \\
\hline$(N=118)$ & $(0.061)$ & (0.105) & $(0.134)$ & $(0.107)$ & $(0.041)$ & $(0.165)$ \\
\hline$[\mathrm{MOIm}]^{+}$ & -0.402 & 1.305 & 1.782 & 1.2 & 0.704 & 0.481 \\
\hline$(N=91)$ & $(0.073)$ & $(0.147)$ & $(0.141)$ & $(0.15$ & $(0.05$ & $(0.204)$ \\
\hline$\left[\mathrm{M}_{3} \mathrm{BAm}\right]^{+}$ & -0.545 & 2.365 & 2.462 & 0.577 & 0.601 & 0.263 \\
\hline$(N=58)$ & $(0.076)$ & $(0.163)$ & $(0.181)$ & $(0.172)$ & (0.047) & $(0.177)$ \\
\hline$\left[\mathrm{M}_{2} \mathrm{EIm}\right]^{+}$ & -0.682 & 2.607 & 2.171 & 0.788 & 0.6 & 0.144 \\
\hline$(N=39)$ & $(0.128)$ & $(0.180)$ & $(0.208)$ & $(0.15$ & (0.074) & $(0.306)$ \\
\hline$\left.{ }_{[\mathrm{BMPy}}\right]^{+}$ & -0.500 & 2.304 & 1.997 & 0.975 & 0.725 & -0.100 \\
\hline$(N=41)$ & $(0.134)$ & $(0.200)$ & $(0.232)$ & (0.189) & (0.074) & $(0.316)$ \\
\hline$[\mathrm{NEP}]^{+}$ & -0.696 & 2.605 & 2.501 & 0.795 & 0.677 & 0.050 \\
\hline$(N=31)$ & $(0.089)$ & $(0.123)$ & $(0.216)$ & (0.129) & (0.038) & $(0.128)$ \\
\hline$\left[\mathrm{PM}_{2} \mathrm{Im}\right]^{+}$ & -0.894 & 2.752 & 3.594 & 0.615 & 0.789 & -0.729 \\
\hline$(N=34)$ & $(0.164)$ & $(0.235)$ & $(0.256)$ & $(0.223)$ & (0.097) & $(0.371)$ \\
\hline \multicolumn{7}{|c|}{ Anions } \\
\hline $\begin{array}{l}{\left[(\mathrm{Tf})_{2} \mathrm{~N}\right]^{-}} \\
(N=401)\end{array}$ & 0.000 & 0.000 & 0.000 & 0.000 & 0.000 & 0.000 \\
\hline$\left[\mathrm{BF}_{4}\right]^{-}$ & -0.107 & 0.422 & 1.222 & -0.538 & 0.011 & -0.232 \\
\hline$(N=225)$ & $(0.06$ & $(0.123)$ & (0.139) & $(0)$ & $(0.0$ & $(0.185)$ \\
\hline$\left[\mathrm{PF}_{6}\right]^{-}$ & -0.330 & 0.814 & 0.100 & -0.543 & -0.226 & 0.704 \\
\hline$(N=108)$ & $(0.085)$ & $(0.130)$ & $(0.122)$ & $(0.122)$ & $(0.054)$ & $(0.227)$ \\
\hline$\left[\mathrm{EtSO}_{4}\right]^{-}$ & -0.334 & 0.277 & 3.058 & -0.939 & -0.136 & 0.359 \\
\hline & $(0.116)$ & (0.209) & $(0.240)$ & $(0.201)$ & $(0.089)$ & $(0.331)$ \\
\hline$[\text { Trif }]^{-}$ & -0.256 & 0.307 & 1.716 & -0.365 & 0.034 & -0.088 \\
\hline$(N=73)$ & $(0.093)$ & $(0.163)$ & $(0.181)$ & $(0.137)$ & $(0.060)$ & $(0.241)$ \\
\hline$\left[\mathrm{F}_{3} \mathrm{Ac}\right]^{-}$ & -0.403 & 0.320 & 3.155 & -0.175 & -0.033 & 0.255 \\
\hline & $(0.146)$ & $(0.349)$ & $(0.758)$ & $(0.812)$ & $(0.087)$ & $(0.371)$ \\
\hline$\left[\mathrm{OtSO}_{4}\right]^{-}$ & 0.222 & -0.148 & 2.451 & -1.049 & 0.035 & 0.313 \\
\hline & $(0.117)$ & $(0.186)$ & $(0.207)$ & $(0.177)$ & $(0.081)$ & $(0.311)$ \\
\hline$[\mathrm{SCN}]^{-}$ & -0.774 & 1.513 & 3.384 & -1.588 & -0.119 & 0.354 \\
\hline & $(0.167)$ & $(0.350)$ & $(0.785)$ & $(0.813)$ & $(0.102)$ & $(0.384)$ \\
\hline
\end{tabular}

${ }^{a}$ Cation and anion abbreviations are given in the footnote to Table 2 . ${ }^{b}$ Number of experimental data points associated with the specified ion.

$=11.03)$; in $\left([\mathrm{MBIm}]^{+}\left[\mathrm{PF}_{6}\right]^{-}\right)(\log K($ calcd $)=11.29$ versus $\log K($ exptl $)=10.65)$; and in $\left([\mathrm{MOIm}]^{+}\left[\mathrm{PF}_{6}\right]^{-}\right)(\log K($ calcd $)$ $=11.053$ versus $\log K($ exptl $)=9.930)$. The hydrogen-bond acidity solute descriptor of acetaminophen $(\mathbf{A}=1.040)$ was much larger than those of linear alcohols that were used in deriving the earlier values. The hydrogen-bond acidity solute descriptor of alcohol solutes typically falls in the $\mathbf{A}=0.310$ to $\mathbf{A}=0.430$ range. The calculated gas to RTIL partition coefficients of acetaminophen based on the equation coefficients in Table 2 are in much closer agreement with the experimental data: $\left([\mathrm{MOIm}]^{+}\left[\mathrm{BF}_{4}\right]^{-}\right)(\log K($ calcd $)=11.23$ versus $\log K$ $($ exptl $)=11.03)$; in $\left([\mathrm{MBIm}]^{+}\left[\mathrm{PF}_{6}\right]^{-}\right)(\log K($ calcd $)=10.71$ versus $\log K($ exptl $)=10.65)$; and in $\left([\mathrm{MOIm}]^{+}\left[\mathrm{PF}_{6}\right]^{-}\right)(\log K$ $($ calcd $)=10.00$ versus $\log K($ exptl $)=9.93)$.

To assess the predictive capability of eq 12 , we divided the 976 data points into a training set and a test set by selecting every other data point in the complete database. The selection ensured that each ion was equally represented in both the training and test sets. The selected data points became the training set, and the compounds that were left served as the test set. Analysis of the experimental data in the training set gave the cation-specific and anion-specific equation coefficients listed in Table 3S (Supporting Information), with $N=488$, SD $=0.113, R^{2}=0.999$ and $F=2920$. The training set equation coefficients were then used to predict $\log K$ values for 488 compounds in the test set. For the predicted and experimental values we find $\mathrm{SD}=0.128$, average absolute error $(\mathrm{AAE})=$
0.092 , and average error $(\mathrm{AE})=-0.006$. There is therefore very little bias in the predictions using eq 12 (coefficients in Table 3S) with AE equal to $-0.006 \log$ units. The predictive ability of the Goss-modified Abraham model, eq 13, was also assessed through training set and test analyses, with the training set equation coefficients and statistical summary reported in Tables 4S and 5S (Supporting Information). As part of the validation studies training and test sets were also constructed by allowing the SPSS software to randomly select half of the experimental values from the entire database. Very similar results were obtained using this latter method of training and test set construction.

The 955 experimental water-to-RTIL partition coefficients were analyzed in similar fashion according to the following models.

Abraham model:

$$
\begin{aligned}
& \log P=\sum_{\text {cation }}\left(c_{\text {cation }}+e_{\text {cation }} \mathbf{E}+s_{\text {cation }} \mathbf{S}+a_{\text {cation }} \mathbf{A}+\right. \\
& \left.b_{\text {cation }} \mathbf{B}+v_{\text {cation }} \mathbf{V}\right)+ \\
& \sum_{\text {anion }}\left(c_{\text {anion }}+e_{\text {anion }} \mathbf{E}+s_{\text {anion }} \mathbf{S}+a_{\text {anion }} \mathbf{A}+b_{\text {anion }} \mathbf{B}+v_{\text {anion }} \mathbf{V}\right) \\
& \left(N=955, R^{2}=0.997, R_{\text {adj }}^{2}=0.996, \mathrm{SD}=0.139, F=2730\right)
\end{aligned}
$$

Goss-modified Abraham model:

$$
\begin{aligned}
& \log P=\sum_{\text {cation }}\left(c_{\text {cation }}+l_{\text {cation }} \mathbf{L}+s_{\text {cation }} \mathbf{S}+a_{\text {cation }} \mathbf{A}+\right. \\
& \left.b_{\text {cation }} \mathbf{B}+v_{\text {cation }} \mathbf{V}\right)+ \\
& \sum_{\text {anion }}\left(c_{\text {anion }}+l_{\text {anion }} \mathbf{L}+s_{\text {anion }} \mathbf{S}+a_{\text {anion }} \mathbf{A}+b_{\text {anion }} \mathbf{B}+v_{\text {anion }} \mathbf{V}\right) \\
& \left(N=955, R^{2}=0.996, R_{\text {adj }}^{2}=0.995, \mathrm{SD}=0.145, F=2585\right)
\end{aligned}
$$

The calculated cation-specific and anion-specific equation coefficients are listed in Tables 4 and 5, along with their respective standard deviations. Both correlations are statistically very good with standard deviations of $0.139 \log$ units (eq 18) and $0.145 \log$ units (eq 19) for data sets that cover a range of approximately $8.7 \mathrm{log}$ units. See Figures 3 and 4 for a plot of the calculated values based on eqs 18 and 19 against the observed values. Standard deviations were slightly larger for the two $\log P$ correlations. This is to be expected as the experimental $\log P$ values include the experimental uncertainties in the $\log K_{\mathrm{w}}$ values that were used to convert $\log K$ to $\log P$ values (see eq 7). Equations 18 and 19 were validated by performing a training set and test set analysis. To conserve journal space, we give only the test set results. (More detailed computational results, including the correlation coefficients, are reported in Tables $6 \mathrm{~S}$ and $7 \mathrm{~S}$ of the Supporting Information.) The Abraham model training set correlation predicted the 477 experimental $\log P$ values to within a $\mathrm{SD}=0.164$, average absolute error $(\mathrm{AE})=0.124$, and average error $(\mathrm{AE})=0.005$. The Goss-modified Abraham model training set correlation predicted the 477 experimental $\log P$ values to within a $\mathrm{SD}=$ 0.171 , average absolute error $(\mathrm{AE})=0.130$, and average error $(\mathrm{AE})=0.006$. There is therefore very little bias in the predictions using eq 18 and 19 with $\mathrm{AE}$ equal to 0.005 and $0.006 \log$ units, respectively.

The nine sets of cation-specific equation coefficients and eight sets of anion-specific equation coefficients that we have determined for both the Abraham model and the Goss-modified version of the Abraham model can be combined to yield 


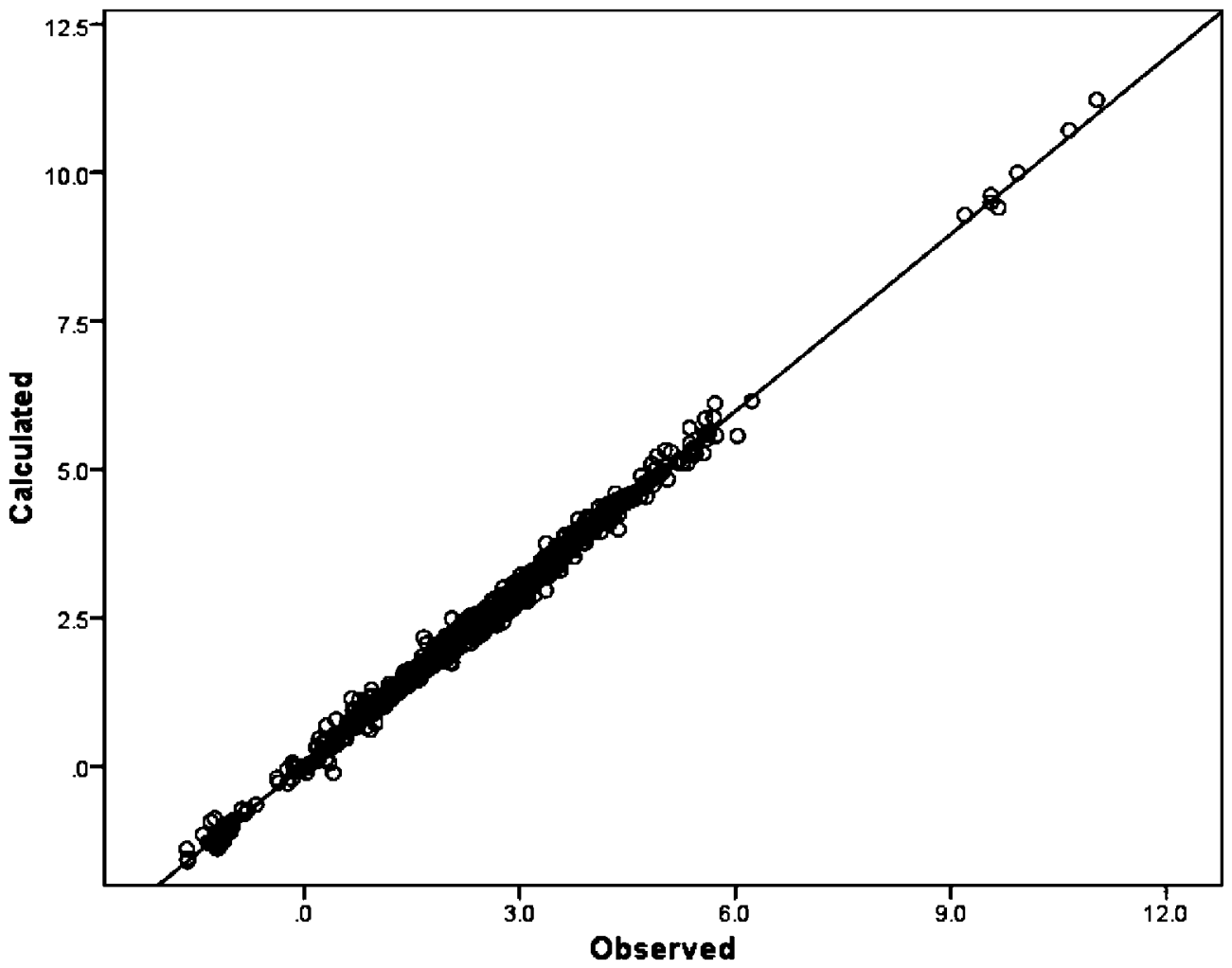

Figure 1. Comparison of experimental $\log K$ data to calculated values based on eq 12 .

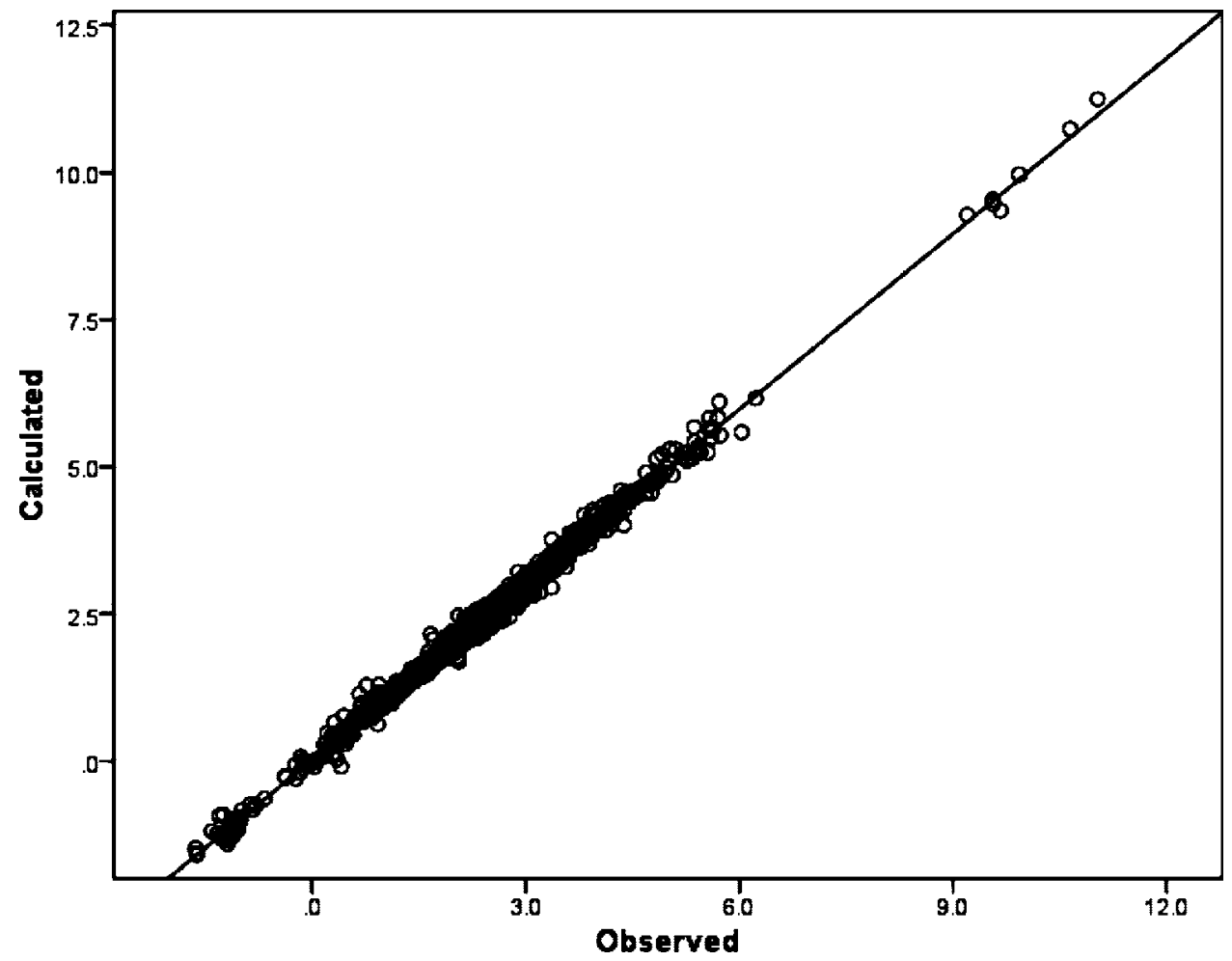

Figure 2. Comparison of experimental $\log K$ data to calculated values based on eq 13 .

predictive $\log K$ and $\log P$ expressions for 72 different RTILs. Past studies ${ }^{1,2}$ have shown that very little loss in predictive ability results from splitting the equation coefficients into separate anion-specific and cation-specific contributions. The computation methodology that we employ of separating the equation coefficients into cation-specific and anion-specific equation coefficients can be applied in principle to other quantitative structure activity relationship (QSAR) and linear free energy relationship (LFER) models. The methodology can also be applied to practical "wet" water-to-RTIL partition coefficient data where the solute is distributed between the water-saturated RTIL and an aqueous phase that is saturated with the RTIL. At the present time there is not sufficient experimental data in the published literature to develop ionspecific equation coefficients for the practical RTIL-water partition systems. 
Table 4. Cation-Specific and Anion-Specific Equation Coefficients for the Abraham Model Water-to-RTIL Correlation (eq 18)

\begin{tabular}{|c|c|c|c|c|c|c|}
\hline $\operatorname{ion}^{a}$ & $c_{\text {ion }}$ & $e_{\text {ion }}$ & $s_{\text {ion }}$ & $a_{\text {ion }}$ & $b_{\text {ion }}$ & $v_{\text {ion }}$ \\
\hline \multicolumn{7}{|c|}{ Cations } \\
\hline$[\mathrm{MEIm}]^{+}$ & -0.025 & 0.399 & 0.244 & -1.447 & -3.698 & 3.105 \\
\hline$(N=208)^{b}$ & $(0.046)$ & $(0.104)$ & & $(0.166)$ & $(0.136)$ & $(0.053)$ \\
\hline$[\mathrm{BMIm}]^{+}$ & -0.045 & 0.417 & 0.117 & -1.514 & -3.998 & 3.320 \\
\hline$(N=346)$ & (0.039) & $(0.078)$ & & & $(0.127)$ & $(0.027)$ \\
\hline${\text { [MHIm }]^{+}}^{\prime}$ & -0.053 & 0.111 & 0.233 & -1.358 & -4.371 & 3.605 \\
\hline$(N=116)$ & (0.048) & $(0.110)$ & $(0.125)$ & (0.156) & (0.139) & $(0.045)$ \\
\hline 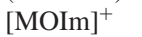 & -0.013 & 0.145 & -0.308 & -1.802 & -3.869 & 3.834 \\
\hline$(N=87)$ & $(0.060)$ & $(0.132)$ & $(0.170)$ & $(0$. & (0. & $(0.059)$ \\
\hline$\left[\mathrm{M}_{3} \mathrm{BAm}\right]^{+}$ & & -0.052 & & -1 . & & 3.210 \\
\hline$(N=56)$ & $(0.070)$ & $(0.155)$ & $(0.179)$ & $(0$. & $(0$. & $(0.058)$ \\
\hline$\left[\mathrm{M}_{2} \mathrm{EIm}\right]^{+}$ & -0.095 & & & -1 . & -4 . & 3.174 \\
\hline$(N=39)$ & $(0.115)$ & $(0.156)$ & $(0$. & $(0$. & (0. & $(0.103)$ \\
\hline$[\mathrm{BMPy}]^{+}$ & -0.079 & 0.402 & & -1. & -3 . & 3.279 \\
\hline$(N=40)$ & & & & & & \\
\hline$[\mathrm{NEP}]^{+}$ & -0.343 & 0.390 & 0.432 & -1.333 & -3.771 & 3.393 \\
\hline$(N=31)$ & (0.131) & $(0.220)$ & $(0.230)$ & $(0.271)$ & (0.1 & $(0.139)$ \\
\hline$\left[\mathrm{PM}_{2} \mathrm{Im}\right]^{+}$ & -0.509 & 0.726 & 0.490 & -0.454 & -3.896 & 2.852 \\
\hline$(N=34)$ & & $(0.205)$ & $(0.274)$ & & & $(0.153)$ \\
\hline \\
\hline$\left[(\mathrm{Tf})_{2} \mathrm{~N}\right]^{-}$ & 0.000 & 0.000 & 0.000 & 0.000 & 0.000 & 0.000 \\
\hline$(N=391)$ & & & & & & \\
\hline$\left[\mathrm{BF}_{4}\right]^{-}$ & -0.074 & 0.088 & 0.317 & 1.324 & -0.512 & -0.240 \\
\hline$(N=221)$ & (0.049) & $(0.108)$ & $(0.137)$ & $(0.164)$ & $(0.163)$ & $(0.051)$ \\
\hline$\left[\mathrm{PF}_{6}\right]^{-}$ & -0.074 & -0.241 & 0.588 & 0.200 & -0.583 & -0.166 \\
\hline$(N=104)$ & $(0.056)$ & $(0.104)$ & $(0.124)$ & $(0.147)$ & $(0.154)$ & $(0.061)$ \\
\hline$\left[\mathrm{EtSO}_{4}\right]^{-}$ & -0.055 & -0.421 & 0.309 & 2.940 & -1.247 & -0.208 \\
\hline$(N=52)$ & (0.097) & (0.182) & $(0.212)$ & $(0.272)$ & $(0.241)$ & $(0.083)$ \\
\hline${\text { [Trif }]^{-}}^{-}$ & -0.178 & -0.167 & 0.412 & 1.607 & -0.362 & -0.054 \\
\hline$(N=73)$ & $(0.080)$ & $(0.150)$ & $(0.183)$ & $(0.210)$ & $(0.179)$ & (0.078) \\
\hline$\left[\mathrm{F}_{3} \mathrm{Ac}\right]^{-}$ & -0.171 & -1.608 & 2.093 & 2.431 & -0.775 & -0.000 \\
\hline$(N=30)$ & (0.107) & (0.382) & $(0.591)$ & $(0.858)$ & & \\
\hline$\left[\mathrm{OtSO}_{4}\right]^{-}$ & 0.000 & -0.226 & 0.054 & 2.652 & -1.164 & 0.689 \\
\hline$(N=56)$ & & $(0.129)$ & $(0.168)$ & $(0.261)$ & $(0.218)$ & (0.111) \\
\hline$[\mathrm{SCN}]^{-}$ & -0.450 & -1.778 & 3.303 & 2.545 & -2.169 & -0.237 \\
\hline$(N=28)$ & (0.190) & (0.397) & $(0.594)$ & $(0.916)$ & $(0.982)$ & $(0.166)$ \\
\hline
\end{tabular}

${ }^{a}$ Cation and anion abbreviations are given in the footnote to Table 2 . ${ }^{b}$ Number of experimental data points associated with the specified ion.
Table 5. Cation-Specific and Anion-Specific Equation Coefficients for the Goss-Modified Abraham Model Water-to-RTIL Set Correlation (eq 19)

\begin{tabular}{|c|c|c|c|c|c|c|}
\hline $\operatorname{ion}^{a}$ & $c_{\text {ion }}$ & $s_{\text {ion }}$ & $a_{\text {ion }}$ & $b_{\text {ion }}$ & $l_{\text {ion }}$ & $v_{\text {ion }}$ \\
\hline \multicolumn{7}{|c|}{ Cations } \\
\hline$\left[_{\mathrm{MEIm}}{ }^{+}\right.$ & 0.075 & 0.436 & -1.350 & -3.932 & 0.092 & 2.789 \\
\hline$(N=208)^{b}$ & $(0.082)$ & $(0.134)$ & $(0.182)$ & $(0.134)$ & $(0.053)$ & $(0.224)$ \\
\hline$\left[\mathrm{BMIm}^{+}\right.$ & 0.034 & 0.366 & -1.360 & -4.291 & 0.073 & 3.072 \\
\hline$(N=344)$ & $(0.068)$ & $(0.118)$ & $(0.129)$ & $(0.121)$ & $(0.048)$ & $(0.191)$ \\
\hline 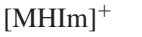 & 0.000 & 0.238 & -1.337 & -4.403 & 0.039 & 3.451 \\
\hline$(N=116)$ & & $(0.130)$ & $(0.163)$ & $(0.130)$ & $(0.051)$ & (0.204) \\
\hline 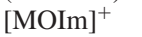 & 0.114 & -0.370 & -1.681 & -4.025 & 0.107 & 3.424 \\
\hline$(N=87)$ & $(0.097)$ & $(0.181)$ & $(0.175)$ & $(0.190)$ & $(0.064)$ & $(0.261)$ \\
\hline$\left[\mathrm{M}_{3} \mathrm{BAm}\right]^{+}$ & -0.039 & 0.473 & -1.183 & -4.453 & -0.077 & 3.505 \\
\hline$(N=56)$ & $(0.127)$ & $(0.240)$ & $(0.259)$ & $(0.231)$ & $(0.096)$ & $(0.373)$ \\
\hline$\left[\mathrm{M}_{2} \mathrm{EIm}\right]^{+}$ & 0.000 & 0.497 & -1.758 & -4.055 & 0.110 & 2.803 \\
\hline$(N=39)$ & & $(0.219)$ & $(0.254)$ & $(0.185)$ & $(0.091)$ & (0.374) \\
\hline${ }_{\mathrm{BMPy}}{ }^{+}$ & 0.031 & 0.405 & -1.844 & -4.017 & 0.149 & 2.787 \\
\hline$(N=40)$ & $(0.179)$ & $(0.267)$ & $(0.305)$ & $(0.240)$ & $(0.103)$ & $(0.438)$ \\
\hline$[\mathrm{NEP}]^{+}$ & -0.331 & 0.731 & -1.245 & -3.971 & 0.017 & 3.377 \\
\hline$(N=31)$ & $(0.170)$ & $(0.235)$ & $(0.293)$ & $(0.179)$ & $(0.097)$ & $(0.414)$ \\
\hline$\left[\mathrm{PM}_{2} \mathrm{Im}\right]^{+}$ & -0.520 & 0.995 & -0.052 & -4.434 & 0.170 & 2.412 \\
\hline$(N=34)$ & $(0.202)$ & $(0.288)$ & $(0.314)$ & $(0.273)$ & $(0.118)$ & $(0.457)$ \\
\hline \multicolumn{7}{|c|}{ Anions } \\
\hline$\left[(\mathrm{Tf})_{2} \mathrm{~N}\right]^{-}$ & 0.000 & 0.000 & 0.000 & 0.000 & 0.000 & 0.000 \\
\hline$(N=391)$ & & & & & & \\
\hline$\left[\mathrm{BF}_{4}\right]^{-}$ & -0.031 & 0.234 & 1.151 & -0.368 & 0.061 & -0.453 \\
\hline$(N=221)$ & $(0.089)$ & $(0.153)$ & $(0.173)$ & (0.159) & $(0.056)$ & $(0.235)$ \\
\hline$\left[\mathrm{PF}_{6}\right]^{-}$ & -0.189 & 0.507 & 0.058 & -0.409 & -0.077 & 0.148 \\
\hline$(N=104)$ & $(0.105)$ & $(0.162)$ & $(0.153)$ & $(0.153)$ & $(0.068)$ & $(0.282)$ \\
\hline$\left[\mathrm{EtSO}_{4}\right]^{-}$ & -0.202 & 0.206 & 2.896 & -1.067 & -0.145 & 0.306 \\
\hline$(N=52)$ & $(0.141)$ & $(0.252)$ & $(0.294)$ & $(0.241)$ & (0.099) & $(0.389)$ \\
\hline$[\text { Trif }]^{-}$ & -0.251 & 0.372 & 1.495 & -0.210 & -0.066 & 0.195 \\
\hline$(N=73)$ & (0.114) & (0.189) & $(0.223)$ & $(0.169)$ & $(0.073)$ & $(0.296)$ \\
\hline$\left[\mathrm{F}_{3} \mathrm{Ac}\right]^{-}$ & -0.667 & 0.963 & 2.884 & -0.155 & -0.343 & 1.364 \\
\hline$(N=30)$ & (0.179) & $(0.426)$ & $(0.924)$ & $(0.991)$ & $(0.107)$ & $(0.457)$ \\
\hline$\left[\mathrm{OtSO}_{4}\right]^{-}$ & 0.088 & -0.401 & 2.409 & -0.818 & 0.123 & 0.227 \\
\hline$(N=56)$ & $(0.165)$ & $(0.233)$ & $(0.281)$ & $(0.223)$ & $(0.101)$ & $(0.404)$ \\
\hline$[\mathrm{SCN}]^{-}$ & -0.955 & 2.200 & 2.883 & -1.479 & -0.495 & 1.588 \\
\hline$(N=28)$ & $(0.204)$ & $(0.427)$ & $(0.958)$ & $(0.991)$ & $(0.125)$ & $(0.471)$ \\
\hline
\end{tabular}

${ }^{a}$ Cation and anion abbreviations are given in the footnote to Table 2. ${ }^{b}$ Number of experimental data points associated with the specified ion.

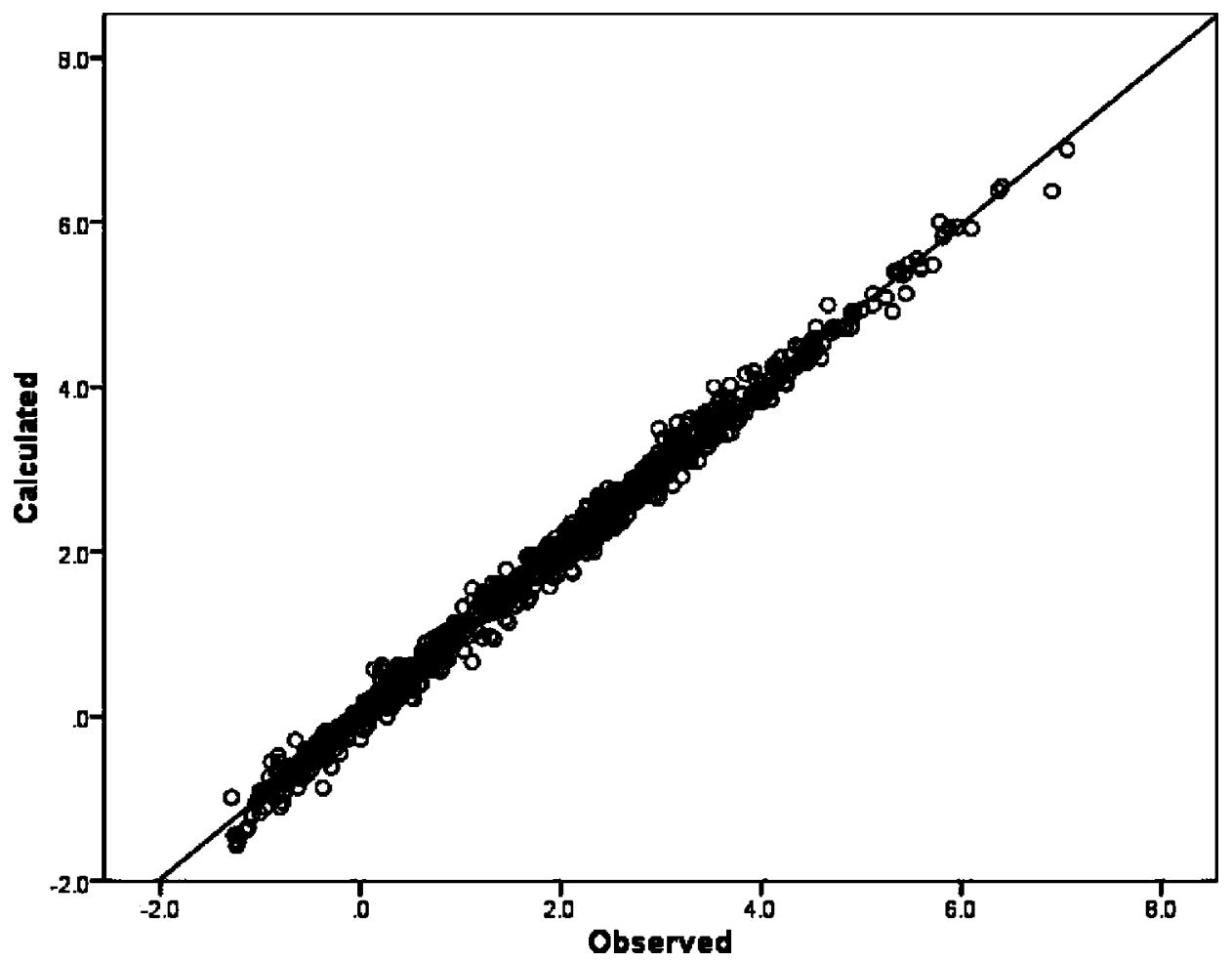

Figure 3. Comparison of experimetnal $\log P$ data to calculated values based on eq 18 . 


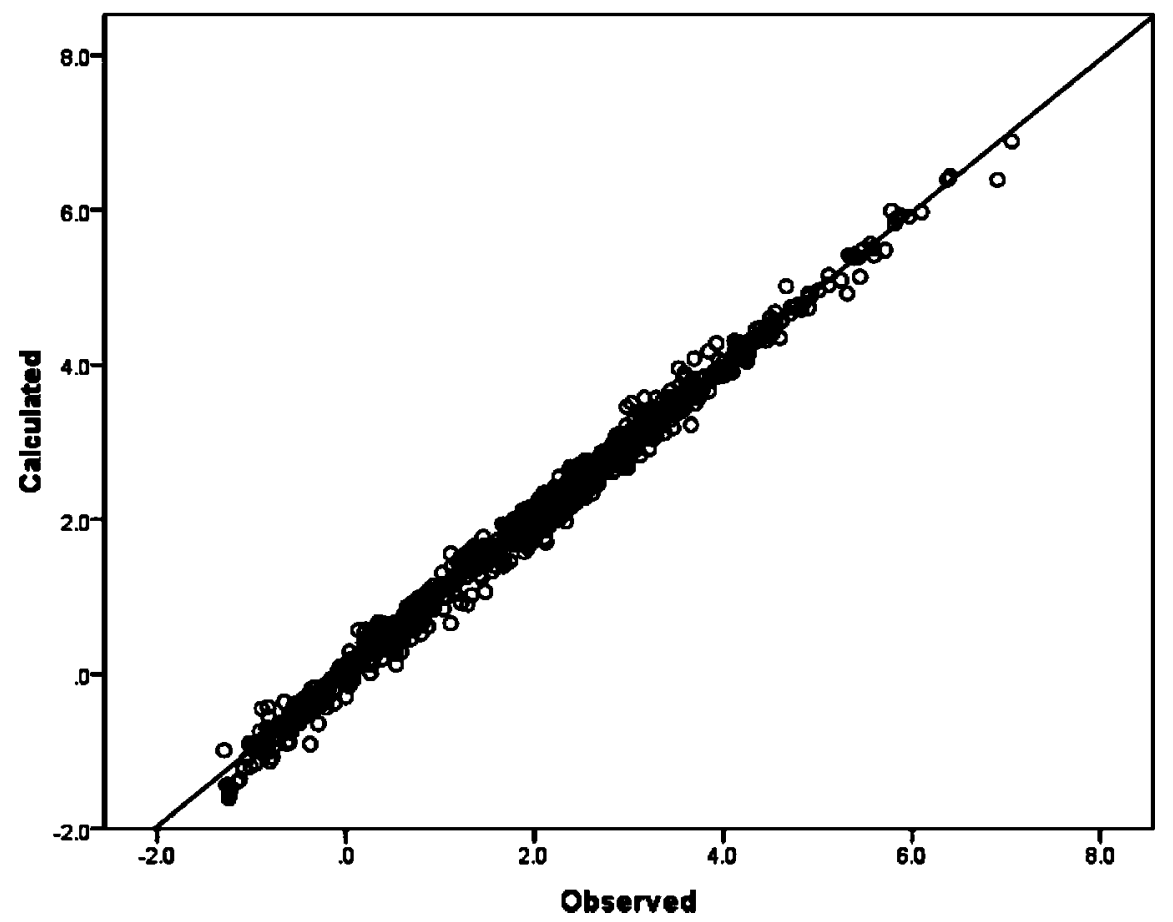

Figure 4. Comparison of experimental $\log P$ data to calculated values based on eq 19.

The list of ion-specific equation coefficients that we have provided in Tables $2-5$ can be easily updated or increased to include more cations/anions as experimental data for more RTILs becomes available. Should one wish to calculate additional ion-specific equation coefficients for the Abraham model or Goss-modified Abraham model there are calculation methods that can be used that would not significantly change the values that have already been calculated. One simple method would be to redefine the regressed "dependent experimental value" as the difference between the experimental $\log K$ or $\log P$ value and the calculated contribution for the ion whose equation coefficients are known.

Abraham model:

regressed value $=\log P-c_{\text {ion }}-e_{\text {ion }} \mathbf{E}-s_{\text {ion }} \mathbf{S}-a_{\text {ion }} \mathbf{A}-$
$b_{\text {ion }} \mathbf{B}-l_{\text {ion }} \mathbf{L}(19 \mathrm{a})$

regressed value $=\log K-c_{\text {ion }}-e_{\text {ion }} \mathbf{E}-s_{\text {ion }} \mathbf{S}-a_{\text {ion }} \mathbf{A}-$$$
\mathrm{b}_{\text {ion }} \mathbf{B}-l_{\text {ion }} \mathbf{L}(20)
$$

Goss-modified Abraham model:

regressed value $=\log P-c_{\text {ion }}-s_{\text {ion }} \mathbf{S}-a_{\text {ion }} \mathbf{A}-b_{\text {ion }} \mathbf{B}-$ $l_{\text {ion }} \mathbf{L}-v_{\text {ion }} \mathbf{V}(21)$

regressed value $=\log K-c_{\text {ion }}-s_{\text {ion }} \mathbf{S}-a_{\text {ion }} \mathbf{A}-b_{\text {ion }} \mathbf{B}-$

$$
l_{\text {ion }} \mathbf{L}-v_{\text {ion }} \mathbf{V}
$$

Equation coefficients of the other counterion could then be computed by regression analysis without altering the values that have already been determined. The computation method allows one to combine experimental data for several RTILs having the desired ion whose equation coefficients one wishes to calculate. By combining data sets, one can calculate equation coefficients for ions that otherwise might not be possible. For example, suppose that one had experimental partition coefficient for 18 different solutes dissolved in trihexyl(tetradecyl)phosphonium bis(trifluoromethylsulfonyl)imide and partition coefficient data for another set of 18 solutes dissolved in trihexyltetradecylphos- phonium tetrafluoroborate. There is not sufficient experimental data for either RTIL to develop a meaningful correlation model; however, when the two data sets are combined there are 36 total measured values. Alternatively, one might measure sufficient experimental partition coefficient data for a given RTIL to determine a RTIL-specific correlation based on the Abraham model. In such instances, one could calculate the equation coefficients, let us say for a new anion, simply by subtracting the respective cation-specific values that were determined previously from the calculated equation coefficients for the entire RTIL (i.e., $c_{\text {anion }}=c_{\text {RTIL }}-c_{\text {cation }} ; e_{\text {anion }}=e_{\text {RTIL }}-e_{\text {cation }}$; etc.). Both computational approaches would ensure that the Abraham model and Goss-modified Abraham model ion-specific equation coefficients that might be reported in future years for RTILs would be compatible with earlier values. The suggested computation methodology also allows one to revise the ionspecific equation coefficients for the cations $\left([\mathrm{NEP}]^{+},\left[\mathrm{PM}_{2} \mathrm{Im}\right]^{+}\right.$, $\left[\mathrm{M}_{2} \mathrm{EIm}\right]^{+}$, and $[\mathrm{MBPy}]^{+}$) and/or anions $\left([\mathrm{SCN}]^{-}\right.$and $\left[\mathrm{AcF}_{3}\right]^{-}$) that were computed from limited experimental data. The ability to compute (or revise) equation coefficients of a given ion without affecting the numerical values that have been calculated for other ions is highly desirable. The popularity of RTILs as solvent media continues to grow, and new ionic liquids continue to be synthesized in response to the growing industrial demand for these rather novel liquid organic compounds.

\section{Acknowledgment}

Jennifer Gibbs thanks the National Science Foundation for support received under NSF-REU Grant (CHE-0648843).

Supporting Information Available: Tables of calculated $\log K$ and $\log P$ values, along with the solute descriptors for all of the compounds considered in the present study; cation-specific and anion-specific equation coefficients; correlation coefficients. This material is available free of charge via the Internet at http:// pubs.acs.org. 


\section{Literature Cited}

(1) Sprunger, L.; Clark, M.; Acree, W. E., Jr.; Abraham, M. H. Characterization of room-temperature ionic liquids by the Abraham model with cation-specific and anion-specific equation coefficients. J. Chem. Inf. Model. 2007, 47, 1123-1129.

(2) Sprunger, L. M.; Proctor, A.; Acree, W. E., Jr.; Abraham, M. H. LFER correlations for room temperature ionic liquids: Separation of equation coefficients into individual cation-specific and anion-specific contributions. Fluid Phase Equilibr. 2008, 265, 104-111.

(3) Proctor, A.; Sprunger, L. M.; Acree, W. E., Jr.; Abraham, M. H. LFER correlations for the solubilising characterization of room temperature ionic liquids containing trifluoro-methanesulfonate and trifluoroacetate anions. Phys. Chem. Liq. 2008, 46, 631-642.

(4) Abraham, M. H. Scales of solute hydrogen-bonding: their construction and application to physicochemical and biochemical processes. Chem. Soc. Reviews 1993, 22, 73-83.

(5) Abraham, M. H.; Ibrahim, A.; Zissimos, A. M. Determination of sets of solute descriptors from chromatographic measurements. J. Chromatogr., A 2004, 1037, 29-47.

(6) Abraham, M. H.; Le, J.; Acree, W. E., Jr. The solvation properties of the aliphatic alcohols. Collect. Czech. Chem. Commun. 1999, 64, 1748 1760.

(7) Abraham, M. H.; Whiting, G. S.; Carr, P. W.; Ouyang, H. Hydrogen bonding. Part 45. The solubility of gases and vapors in methanol at $298 \mathrm{~K}$ : An LFER analysis. J. Chem. Soc., Perkin Trans. 1998, 2, 1385-1390.

(8) Abraham, M. H.; Whiting, G. S.; Shuely, W. J.; Doherty, R. M. The solubility of gases and vapors in ethanol-The connection between gaseous solubility and water-solvent partition. Can. J. Chem. 1998, 76, 703709.

(9) Abraham, M. H.; Platts, J. A.; Hersey, A.; Leo, A. J.; Taft, R. W. Correlation and Estimation of gas-chloroform and water-chloroform partition coefficients by a linear free energy relationship method. J. Pharm. Sci. 1999 , $88,670-679$.

(10) Abraham, M. H.; Le, J.; Acree, W. E., Jr.; Carr, P. W. Solubility of gases and vapours in propan-1-ol at 298 K. J. Phys. Org. Chem. 1999, $12,675-680$.

(11) Goss, K.-U. Predicting the equilibrium partitioning of organic compounds using just one linear solvation energy relationship (LSER). Fluid Phase Equilib. 2005, 233, 19-22.

(12) Niederer, C.; Goss, K.-U.; Schwarzenbach, R. P. Sorption equilibrium of a wide spectrum of organic vapors in Leonardite humic acid: Modeling of experimental data. Environ. Sci. Technol. 2006, 40, 5374 5379 .

(13) Roth, C. M.; Goss, K.-U.; Schwarzenbach, R. P. Sorption of a diverse set of organic vapors to urban aerosols. Environ. Sci. Technol. 2005, 39, 6638-6643.

(14) Goss, K.-U. Prediction of the temperature dependency of Henry's law constant using poly-parameter linear free energy relationships. Chemosphere 2006, 64, 1369-1374.

(15) Niederer, C.; Schwarzenbach, R. P.; Goss, K.-U. Elucidating differences in the sorption properties of 10 humic and fulvic acids for polar and nonpolar organic chemicals. Environ. Sci. Technol. 2007, 41, 67116717.

(16) Tuelp, H. C.; Goss, K.-U.; Schwarzenbach, R. P.; Fenner, K. Experimental determination of LSER parameters for a set of 76 diverse pesticides and pharmaceuticals. Environ. Sci. Technol. 2008, 42, 2034 2040.

(17) Baltazar, Q. Q.; Leininger, S. K.; Anderson, J. L. Binary ionic liquid mixtures as gas chromatography stationary phases for improving the separation selectivity of alcohols and aromatic compounds. J. Chromatogr., A 2008, 1182, 119-127.

(18) Anderson, J. L. Unpublished data.

(19) Mizuuchi, H.; Jaitely, V.; Murdan, S.; Florence, A. T. Room temperature ionic liquids and their mixtures: Potential pharmaceutical solvents. Eur. J. Pharm. Sci. 2008, 33, 326-331.

(20) Domanska, U.; Marciniak, A. Measurements of activity coefficients at infinite dilution of aromatic and aliphatic hydrocarbons, alcohols, and water in the new ionic liquid [EMIM][SCN] using GLC. J. Chem. Thermodyn. 2008, 40, 860-866.

(21) Yang, X.-J.; Wu, J.-S.; Ge, M.-L.; Wang, L.-S.; Li, M.-Y. Activity coefficients at infinite dilution of alkanes, alkenes, and alkyl benzenes in 1-hexyl-3-methylimidazolium trifluoromethanesulfonate using gas-liquid chromatography. J. Chem. Eng. Data 2008, 53, 1220-1222.

(22) Ge, M.-L.; Wu, J.-S.; Wang, M.-H.; Wang, L.-S. Activity coefficients at infinite dilution of polar solutes in 1-propyl-2,3-dimethylimidazolium tetrafluoroborate using gas-liquid chromatography. J. Chem. Eng. Data 2008, 53, 871-873.
(23) Ge, M.-L.; Wang, L.-S.; Wu, J.-S.; Zhou, Q. Activity coefficients at infinite dilution of organic solutes in 1-ethyl-3-methylimidazolium tetrafluoroborate using gas-liquid chromatography. J. Chem. Eng. Data 2008, 53, 1970-1974.

(24) Wang, M.-H.; Wu, J.-S.; Wang, L.-S.; Li, M.-Y. Activity coefficients at infinite dilution of alkanes, alkenes, and alkylbenzenes in 1-propyl2,3-dimethylimidazolium tetrafluoroborate using gas-liquid chromatography. J. Chem. Eng. Data 2007, 52, 1488-1491.

(25) Mutelet, F.; Jaubert, J.-N. Accurate measurements of thermodynamic properties of solutes in ionic liquids using inverse gas chromatography. J. Chromatogr., A 2006, 1102, 256-267.

(26) O’Mahony, A. M.; Silvester, D. S.; Aldous, L.; Hardacre, C.; Compton, R. G. The electrochemical reduction of hydrogen sulfide on platinum in several room temperature ionic liquids. J. Phys. Chem. C 2008, 112, 7725-7730.

(27) Kilaru, P. K.; Condemarin, R. A.; Scovazzo, P. Correlations of lowpressure carbon dioxide and hydrocarbon solubilities in imidazolium-, phosphonium-, and ammonium-based room-temperature ionic liquids. Part 1. Using surface tension. Ind. Eng. Chem. Res. 2008, 47, 900-909. Kumelan, J.; Perez-Salado Kamps, A.; Tuma, D.; Maurer, G. Solubility of the single gases methane and xenon in the ionic liquid $[\mathrm{hmim}]\left[\mathrm{Tf}_{2} \mathrm{~N}\right]$. Ind. Eng. Chem. Res. 2007, 46, 8236-8240.

(28) Jacquemin, J.; Husson, P.; Majer, V.; Costa Gomes, M. F. Influence of the cation on the solubility of $\mathrm{CO}_{2}$ and $\mathrm{H}_{2}$ in ionic liquids based on the bis(trifluoromethyl-sulfonyl)imide anion. J. Solution Chem. 2007, 36, 967979.

(29) Zhang, J.; Zhang, Q.; Qiao, B.; Deng, Y. Solubilities of the gaseous and liquid solutes and their thermodynamics of solubilization in the novel room-temperature ionic liquids at infinite dilution by gas chromatography. J. Chem. Eng. Data 2007, 52, 2277-2283.

(30) Deenadayalu, N.; Letcher, T. M.; Reddy, P. Determination of activity coefficients at infinite dilution of polar and nonpolar solutes in the ionic liquid 1-ethyl-3-methyl- imidazolium bis(trifluoromethylsulfonyl)imidate using gas-liquid chromatography at the temperature 303.15 or 318.15 K. J. Chem. Eng. Data 2005, 50, 105-108.

(31) Finotello, A.; Bara, J. E.; Camper, D.; Noble, R. D. Roomtemperature ionic liquids: Temperature dependence of gas solubility selectivity. Ind. Eng. Chem. Res. 2008, 47, 3453-3459.

(32) Shiflett, M. B.; Yokozeki, A. Solubility differences of halocarbon isomers in ionic liquid [emim][Tf 2 N]. J. Chem. Eng. Data 2007, 52, 20072015.

(33) Silvester, D. S.; Ward, K. R.; Aldous, L.; Hardacre, C.; Compton, R. G. The electrochemical oxidation of hydrogen at activated platinum electrodes in room temperature ionic liquids as solvents. J. Electroanal. Chem. 2008, 618, 53-60.

(34) Dyson, P. J.; Laurenczy, G.; Ohlin, C. A.; Vallance, J.; Welton, T. Determination of hydrogen concentration in ionic liquids and the effect (or lack of) on rates of hydrogenation. Chem. Commun. 2003, 2418-2419.

(35) Domanska, U.; Marciniak, A. Activity coefficients at infinite dilution measurements for organic solutes and water in the ionic liquid 1-butyl-3methylimidazolium trifluoromethanesulfonate. J. Phys. Chem. 2007, 111, 11984-11988

(36) Shimoyama, Yusuke; Hirayama, Takeshi; Iwai, Yoshio. Measurement of infinite dilution activity coefficients of alcohols, ketones, and aromatic hydrocarbons in 4-methyl- $N$-butylpyridinium tetrafluoroborate and 1-butyl-3-methylimidazolium hexafluorophosphate by gas-liquid chromatography. J. Chem. Eng. Data 2008, 53, 2106-2111.

(37) Cheng, X.; Mu, T.; Wang, X.; Guo, X.; Zou, L. Low pressure solubilities of vinyl chloride in ionic liquids. J. Chem. Eng. Data 2008, 53, 2807-2809.

(38) Yokozeki, A.; Shiflett, Mark B. Ammonia solubilities in roomtemperature ionic liquids. Ind. Eng. Chem. Res. 2007, 46, 1605-1610.

(39) Alonso, L.; Arce, A.; Francisco, M.; Rodriguez, O.; Soto, A. Gasoline desulfurization using extraction with $\left[\mathrm{C}_{8} \mathrm{mim}\right]\left[\mathrm{BF}_{4}\right]$ ionic liquid. AIChE J. 2007, 53, 3108-3115.

(40) Alonso, L.; Arce, A.; Francisco, M.; Soto, A. Measurement and correlation of liquid-liquid equilibria of two imidazolium ionic liquids with thiophene and methylcyclohexane. J. Chem. Eng. Data 2007, 52, 24092412 .

(41) Alonso, L.; Arce, A.; Francisco, M.; Soto, A. Solvent extraction of thiophene from $n$-alkanes $\left(\mathrm{C}_{7}, \mathrm{C}_{12}\right.$ and $\left.\mathrm{C}_{16}\right)$ using the ionic liquid $\left[\mathrm{C}_{8} \mathrm{mim}\right]\left[\mathrm{BF}_{4}\right]$. J. Chem. Thermodyn. 2008, 40, 966-972.

(42) Alonso, L.; Arce, A.; Francisco, M.; Soto, A. (Liquid + liquid) equilibria of $\left[\mathrm{C}_{8} \mathrm{mim}\right]\left[\mathrm{NTf}_{2}\right]$ ionic liquid with a sulfur-component and hydrocarbons. J. Chem. Thermodyn. 2008, 40, 265-270.

(43) Alonso, L.; Arce, A.; Francisco, M.; Soto, A. Phase behaviour of 1-methyl-3-octylimidazolium bis[trifluoromethylsulfonyl]imide with thiophene and aliphatic hydrocarbons: The influence of $n$-alkane chain length. Fluid Phase Equilib. 2008, 263, 176-181. 
(44) Alonso, L.; Arce, A.; Francisco, M.; Soto, A. Liquid-liquid equilibria for $\left[\mathrm{C}_{8} \mathrm{mim}\right]\left[\mathrm{NTf}_{2}\right]+$ thiophene $+2,2,4$-trimethylpentane or + toluene. J. Chem. Eng. Data 2008, 53, 1750-1755.

(45) Alonso, L.; Arce, A.; Francisco, M.; Soto, A. Thiophene separation from aliphatic hydrocarbons using 1-ethyl-3-methylimidazolium ethylsulfate ionic liquid. Fluid Phase Equilib 2008, 270, 97-102.

(46) Shiflett, M. B.; Yokozeki, A. Liquid-liquid equilibria in binary mixtures of 1,3-propanediol + ionic liquids $[\mathrm{bmim}]\left[\mathrm{PF}_{6}\right],[\mathrm{bmim}]\left[\mathrm{BF}_{4}\right]$, and [emim] $\left[\mathrm{BF}_{4}\right]$. J. Chem. Eng. Data 2007, 52, 1302-1306.

(47) Arce, A.; Rodriguez, O.; Soto, A. A comparative study on solvents for separation of tert-amyl ethyl ether and ethanol mixtures. New experimental data for 1-ethyl-3-methyl imidazolium ethyl sulfate ionic liquid. Chem. Eng. Sci. 2006, 61, 6929-6935.

(48) Arce, A.; Rodriguez, H.; Soto, A. Purification of ethyl tert-butyl ether from its mixtures with ethanol by using an ionic liquid. Chem. Eng. J. 2006, 115, 219-223.

(49) Arce, A.; Rodriguez, H.; Soto, A. Effect of anion fluorination in 1-ethyl-3-methyl-imidazolium as solvent for the liquid extraction of ethanol from ethyl tert-butyl ether. Fluid Phase Equilib. 2006, 242, 164-168.
(50) Arce, A.; Rodriguez, O.; Soto, A. tert-Amyl ethyl ether separation from its mixtures with ethanol using the 1-butyl-3-methylimidazolium trifluoromethanesulfonate ionic liquid: Liquid-liquid equilibrium. Ind. Eng. Chem. Res. 2004, 43, 8323-8327.

(51) Deenadayalu, N.; Ngcongo, K. C.; Letcher, T. M.; Ramjugernath, D. Liquid-liquid equilibria for ternary mixtures (an ionic liquid + benzene + heptane or hexadecane) at $T=298.2 \mathrm{~K}$ and atmospheric pressure. J. Chem. Eng. Data 2006, 51, 988-991.

(52) Pereiro, A. B.; Rodríguez, A. Binary mixtures containing OMIM PF6: Density, speed of sound, refractive index, and LLE with hexane, heptanes, and 2-propanol at several temperatures. Phys. Chem. Liq. 2008, 46, 162-174.

Received for review December 9, 2008 Revised manuscript received February 16, 2009 Accepted February 26, 2009

IE801898J 